\title{
A Salt-Assisted Combustion Method to Prepare Well-Dispersed Octahedral $\mathrm{MnCr}_{2} \mathrm{O}_{4}$ Spinel Nanocrystals
}

\author{
Yuping Tong, Juntao Ma, Shunbo Zhao, Hongyuan Huo, and Hailong Zhang \\ School of Civil Engineering and Communication, North China University of Water Resources and Electric Power, \\ Zhengzhou 450011, China
}

Correspondence should be addressed to Yuping Tong; tongqzm@163.com

Received 12 April 2015; Accepted 17 May 2015

Academic Editor: Hassan Karimi-Maleh

Copyright (C) 2015 Yuping Tong et al. This is an open access article distributed under the Creative Commons Attribution License, which permits unrestricted use, distribution, and reproduction in any medium, provided the original work is properly cited.

Well-dispersed nanocrystalline $\mathrm{MnCr}_{2} \mathrm{O}_{4}$ was prepared by a salt-assisted combustion process using low-toxic glycine as fuel and $\mathrm{Mn}\left(\mathrm{NO}_{3}\right)_{2}$ and $\mathrm{Cr}\left(\mathrm{NO}_{3}\right)_{3} \cdot 9 \mathrm{H}_{2} \mathrm{O}$ as raw materials. The obtained products were characterized by X-ray Diffraction (XRD), Fourier Transform Infrared (FT-IR) spectroscopy, Raman spectroscopy, Transmission Electron Microscopy (TEM), and Scanning Electron Microscopy (SEM). The fabrication process was monitored by thermogravimetric and differential thermal analysis (TG-DTA). The phase formation process was detected by XRD, and $\mathrm{MnCr}_{2} \mathrm{O}_{4}$ single phase with high crystallinity was formed at $700^{\circ} \mathrm{C}$. TEM and SEM images revealed that the products were composed of well-dispersed octahedral nanocrystals with an average size of $80 \mathrm{~nm}$. Inert salt-LiCl played an important role in breaking the network structure of agglomerated nanocrystallites.

\section{Introduction}

In recent years, nanostructured materials have found extensive applications such as catalytic, electrochemical sensors for biological and pharmaceutical analysis, and high capacity anode materials due to exceptional properties of nanostructured materials where at least one dimension of the structure is less than $100 \mathrm{~nm}[1-5]$.

Mixed metal oxides represented by the general formula $\mathrm{AB}_{2} \mathrm{O}_{4}$ are spinel structure oxides with a variety of interesting electrical, magnetic, and optical properties $[6,7]$. Due to the exceptional properties, the complexes are widely applied in wastewater treatment and photocatalytic field $[8,9]$. Generally, A is bivalent cation, and B is trivalent cation. A cation is in fourfold coordination and $\mathrm{B}$ cation retains the sixfold coordination. $\mathrm{MnCr}_{2} \mathrm{O}_{4}$ is ferromagnetic spinel, in which the $\mathrm{Mn}^{2+}$ cations occupy the tetrahedral (A) sites and the $\mathrm{Cr}^{3+}$ cations occupy the octahedral (B) sites. Due to their remarkable magnetic and electric properties, they have received broad interests in theoretical and experimental investigations for application purpose [10, 11]. Many reports found that $\mathrm{MnCr}_{2} \mathrm{O}_{4}$ spinel structure was usually presented on the top of chromic scale as coatings in carburization attack in many petrochemical industrial processes $[12,13]$.
Moreover, $\mathrm{MnCr}_{2} \mathrm{O}_{4}$ exhibits much better resistance to carbonaceous attack than $\mathrm{Cr}_{2} \mathrm{O}_{3}$ [14]. It is reported that $\mathrm{MnCr}_{2} \mathrm{O}_{4}$ nanocomposite has a vital effect on the $\mathrm{NO}_{2}$ sensing property for YSZ-based potentiometric sensor [15]. Therefore there has been a growing interest focused on the investigation of synthesis and properties of nanostructured $\mathrm{MnCr}_{2} \mathrm{O}_{4}$ materials.

Traditionally, $\mathrm{MnCr}_{2} \mathrm{O}_{4}$ was prepared by solid-state reaction using a stoichiometric mixture of $\mathrm{MnO}_{2}$ and $\mathrm{Cr}_{2} \mathrm{O}_{3}$ powders with an atomic ratio of $1: 1$ at $1000^{\circ} \mathrm{C}$ sintering for $10 \mathrm{~h}[16$, 17]. Although it was simple, this process had several serious drawbacks, including the high reaction temperature and the limited degree of chemical homogeneity. Precursor method was one of the typical strategies to synthesize well-dispersible nanometal oxides [18]. In our previous study, the complex oxides nanocrystalline were easily obtained by a salt-assisted combustion method $[19,20]$. In this paper, we present the preparation and characterization of well-dispersed $\mathrm{MnCr}_{2} \mathrm{O}_{4}$ nanocrystals by the salt-assisted combustion method.

\section{Experiment}

2.1. Preparation of $\mathrm{MnCr}_{2} \mathrm{O}_{4}$ Nanocrystals. All reagents were of analytical grade and used without further purification. 
The fabrication procedure of $\mathrm{MnCr}_{2} \mathrm{O}_{4}$ can be referred to in the literature [20]. $\mathrm{Mn}\left(\mathrm{NO}_{3}\right)_{2}$ and $\mathrm{Cr}\left(\mathrm{NO}_{3}\right)_{3} \cdot 9 \mathrm{H}_{2} \mathrm{O}$ were used as precursors of $\mathrm{Mn}$ and $\mathrm{Cr}$, respectively. The molar ratio of $\mathrm{Mn}$ : Cr was 1:2. Glycine was used as fuel. Firstly, an appropriate amount of glycine was dissolved in deionized water. Then proper amounts of $\mathrm{Mn}\left(\mathrm{NO}_{3}\right)_{2}, \mathrm{Cr}\left(\mathrm{NO}_{3}\right)_{3} \cdot 9 \mathrm{H}_{2} \mathrm{O}$, and $\mathrm{LiCl}$ were added to the glycine aqueous solution in turn. The mixed solution was vigorously stirred for $2 \mathrm{~h}$ at $60^{\circ} \mathrm{C}$ and evaporated at $120^{\circ} \mathrm{C}$. At this stage, the viscous liquids were swelled with the evolution of gases, and self-propagating solution combustion slowly occurred to yield the loose powders. The obtained powders were calcined at different temperatures ranging from 400 to $700^{\circ} \mathrm{C}$ for $3 \mathrm{~h}$ in air. In order to remove salt, the as-calcined powders were filtered and washed with hot deionized water and ethanol until the $\mathrm{Cl}^{-}$was eliminated. Finally, the product was dried in an oven at $80^{\circ} \mathrm{C}$. To study the influence of the addition of inert salt during the reaction on the product particles, $\mathrm{MnCr}_{2} \mathrm{O}_{4}$ nanocrystals were also prepared under the condition without adding $\mathrm{LiCl}$ in the process of reaction.

2.2. Instrumentation. The thermal decomposition process of the sol was investigated by simultaneous thermogravimetric and differential thermal analysis (TG-DTA) using Beijing WCT-2A thermal analyzer from $50^{\circ} \mathrm{C}$ to $750^{\circ} \mathrm{C}$, with a heating rate of $20^{\circ} \mathrm{C} / \mathrm{min}$ and $\mathrm{Al}_{2} \mathrm{O}_{3}$ as reference. The crystalline phase structure was determined by Bruker D8 Advance Xray diffractometer (XRD) using $\mathrm{Cu} \mathrm{K} \alpha$ radiation. FT-IR spectra of $\mathrm{KBr}$ powder-pressed pellets were recorded on a Bruker Vector 22 spectrometer. Raman spectra were run on a Renishaw in Raman microscope. Transmission electron microscopy (TEM) image was recorded on a JEOL JEM-2100 transmission electron microscope operating at $200 \mathrm{kV}$. Scanning electron microscopy (SEM) image was recorded on a JSM-7500F scanning electron microscope. Energy dispersive spectrum (EDS) analysis was taken with EDAX electron microscope.

\section{Results and Discussion}

3.1. TG-DTA Analysis. In order to study the thermal behavior of the precursor, the corresponding TG and DTA curves are shown in Figure 1. The TG curve shows that the weight loss started at $50^{\circ} \mathrm{C}$; the first endothermic peak can be attributed to the removal of the solvent water in the precursor. The exothermic peaks at $228^{\circ} \mathrm{C}$ and $352^{\circ} \mathrm{C}$ with the weight loss $(12.45 \%)$ are due to the burning of the glycine. The third exothermic peak is related to the formation of the oxide as no other exothermic process was observed after $457^{\circ} \mathrm{C}$. These are identical to the XRD patterns (Figure 2). The measured overall weight loss $34.01 \%$ was slightly less than the theoretical weight loss $37.14 \%$, which may be due to the incomplete burning of the glycine in the self-propagation process.

3.2. XRD Analysis. The $\mathrm{MnCr}_{2} \mathrm{O}_{4}$ nanocrystals were obtained by calcining the precursor powders at sintering temperatures 400 to $700^{\circ} \mathrm{C}$. The phase formation process was detected by XRD. The XRD patterns are shown in Figure 2, from which a clear transition process of the crystal phase

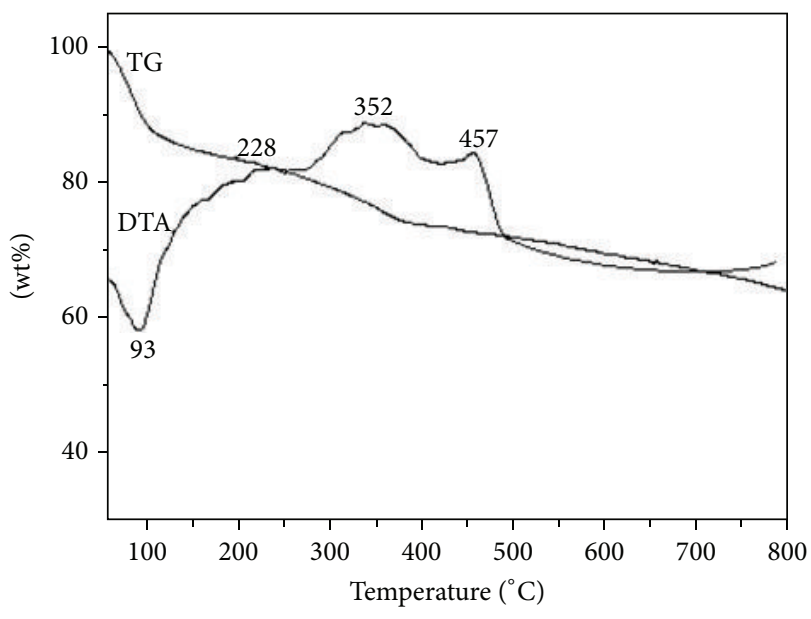

Figure 1: TG-DTA curves of $\mathrm{MnCr}_{2} \mathrm{O}_{4}$ precursor obtained via dissolving the mixture of $\mathrm{Mn}\left(\mathrm{NO}_{3}\right)_{2}$ and $\mathrm{Cr}\left(\mathrm{NO}_{3}\right)_{3} \cdot 9 \mathrm{H}_{2} \mathrm{O}$ (with molar ratio of $\mathrm{Mn} / \mathrm{Cr}=1: 2$ ) with glycine solution and subsequent self-propagating combustion.

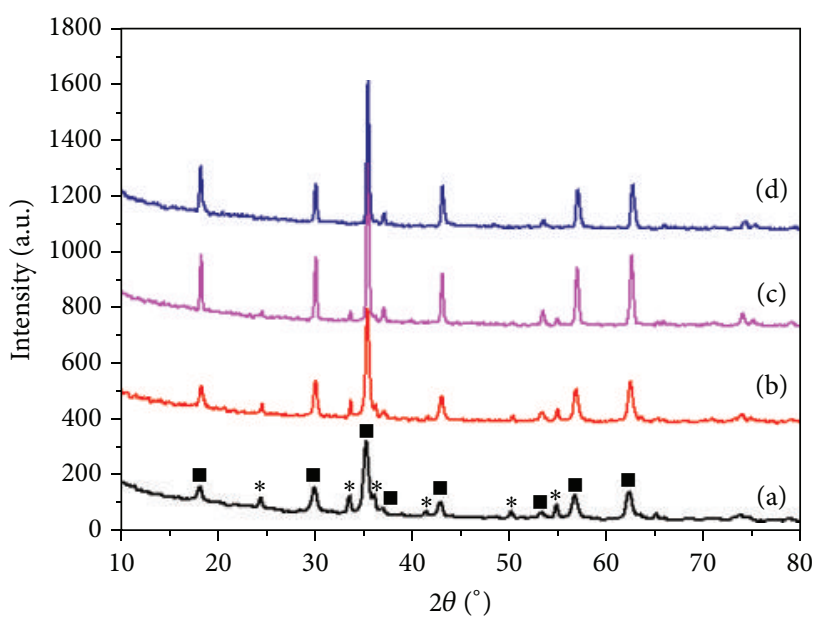

FIGURE 2: XRD patterns of the samples obtained via $\mathrm{MnCr}_{2} \mathrm{O}_{4}$ precursor calcined at different temperatures for $3 \mathrm{~h}$ : (a) $400^{\circ} \mathrm{C}$, (b) $500^{\circ} \mathrm{C}$, (c) $600^{\circ} \mathrm{C}$, and (d) $700^{\circ} \mathrm{C}$.

can be seen. When the precursor was sintered at $400^{\circ} \mathrm{C}$, it was found that the compounds $\mathrm{MnCr}_{2} \mathrm{O}_{4}$ and $\mathrm{Cr}_{2} \mathrm{O}_{3}$ existed simultaneously. With the temperature increasing, the characteristic peaks of $\mathrm{Cr}_{2} \mathrm{O}_{3}$ became weaker and the peaks of $\mathrm{MnCr}_{2} \mathrm{O}_{4}$ became stronger. When the temperature was $700^{\circ} \mathrm{C}$, a single phase of $\mathrm{MnCr}_{2} \mathrm{O}_{4}$ (JCPDS: 054-0876) was formed and no impure peaks were observed, which indicated that the pure $\mathrm{MnCr}_{2} \mathrm{O}_{4}$ with cubic structure could be successfully synthesized by this method. For $\mathrm{MnCr}_{2} \mathrm{O}_{4}$ nanocrystals, there are several characteristic peaks at $2 \theta=$ $18.33^{\circ}, 30.31^{\circ}, 35.65^{\circ}, 43.05^{\circ}, 56.99^{\circ}$, and $62.54^{\circ}$; the interstices of corresponding crystal faces are $0.484 \mathrm{~nm}, 0.295 \mathrm{~nm}$, $0.252 \mathrm{~nm}, 0.210 \mathrm{~nm}, 0.162 \mathrm{~nm}$, and $0.148 \mathrm{~nm}$, respectively.

3.3. Raman and IR Analysis. Raman and IR spectra of $\mathrm{MnCr}_{2} \mathrm{O}_{4}$ nanocrystals calcined at $700^{\circ} \mathrm{C}$ are shown in 


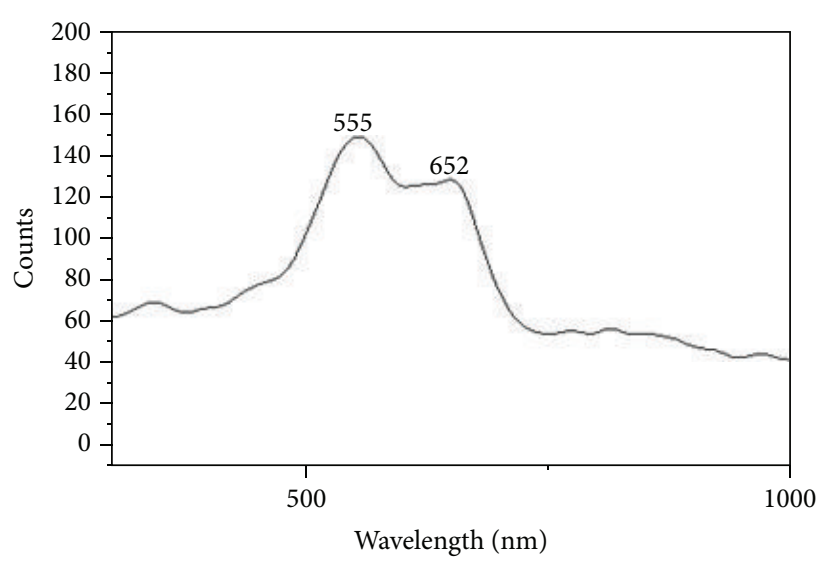

(a)

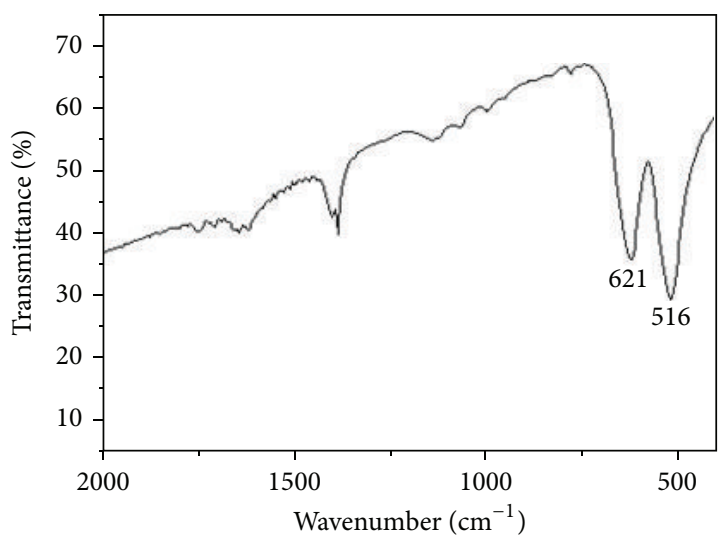

(b)

FIgURE 3: Raman spectrum (a) and IR spectrum (b) of the nanocrystals $\mathrm{MnCr}_{2} \mathrm{O}_{4}$ obtained by precursor calcined at $700^{\circ} \mathrm{C}$.

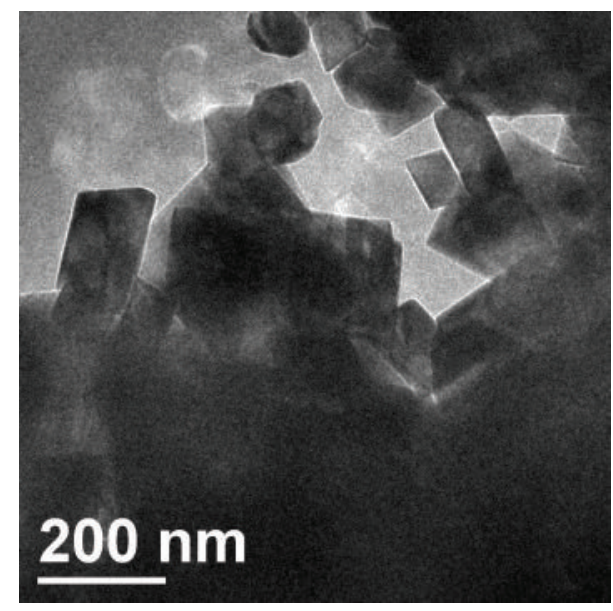

(a)

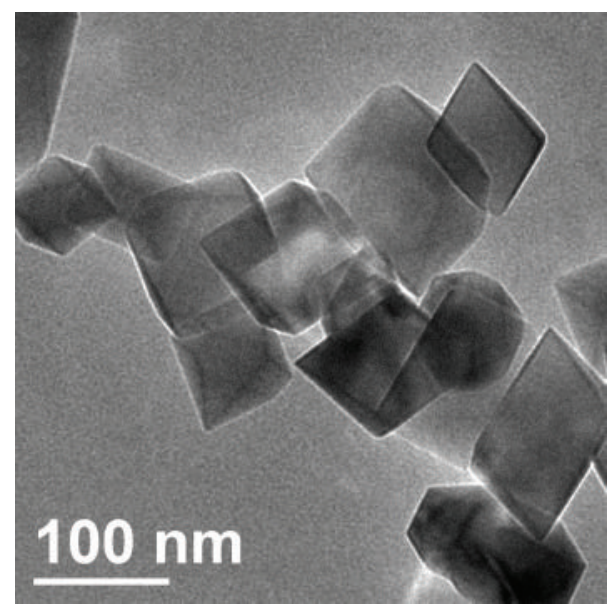

(b)

FIGURE 4: Representative TEM images of the nanocrystals $\mathrm{MnCr}_{2} \mathrm{O}_{4}$ obtained by precursor calcined at $700^{\circ} \mathrm{C}$ for $3 \mathrm{~h}$ : (a) without adding LiCl in the reaction process and (b) adding $\mathrm{LiCl}$ in the reaction process.

Figures 3(a) and 3(b), respectively. The bands at $555 \mathrm{~cm}^{-1}$ and $652 \mathrm{~cm}^{-1}$ are the characteristic vibration peaks of spinel $\mathrm{MnCr}_{2} \mathrm{O}_{4}$ nanocrystals. Figure 3(b) shows the IR spectra of $\mathrm{MnCr}_{2} \mathrm{O}_{4}$ nanocrystals. There are two absorption peaks at $516 \mathrm{~cm}^{-1}$ and $621 \mathrm{~cm}^{-1}$, which are attributed to the $\mathrm{Mn}-\mathrm{O}$ vibration frequency of the metal at tetrahedral clearance and octahedral clearance, respectively [21].

3.4. Morphology Analysis. The size, shape, and agglomeration state of the $\mathrm{MnCr}_{2} \mathrm{O}_{4}$ particles obtained by the salt-assisted combustion method at $700^{\circ} \mathrm{C}$ are shown in Figure 4. TEM image of $\mathrm{MnCr}_{2} \mathrm{O}_{4}$ particles obtained in the reaction process without inert salt is shown in Figure 4(a). It reveals that the $\mathrm{MnCr}_{2} \mathrm{O}_{4}$ particles are composed of cube-like agglomerated structures. As shown in Figure 4(b), $\mathrm{MnCr}_{2} \mathrm{O}_{4}$ particles obtained by the salt-assisted combustion method are uniform in both morphology and crystallite size and are cubic-like with good dispensability. The average size calculated from the TEM image is $80 \mathrm{~nm}$, which is consistent with the result from
XRD data according to Scherrer's equation. It is clear that inert salt- $\mathrm{LiCl}$ played an important role in breaking the network structure of agglomerated nanocrystallines during the reaction.

In order to further investigate the dispersibility of obtained particles, SEM images under different magnifications of $\mathrm{MnCr}_{2} \mathrm{O}_{4}$ particles are shown in Figure 5. It is clear that the average particle size is $80 \mathrm{~nm}$. The nanoparticles are of tetrahedral shape. The SEM micrographs also reveal that the samples have good dispersibility. It can be seen that there are a few abnormal large grains. However, most of the grains are uniform and well-dispersed.

3.5. Crystal Growth Process. As is well known, when solvent evaporates to exceed the saturated solubility of solute in the heating process, solute will precipitate, especially in seed precipitation. Since the self-propagating combustion reaction released a large amount of heat in an instant, the particles could be formed under this condition. The salt precipitation 


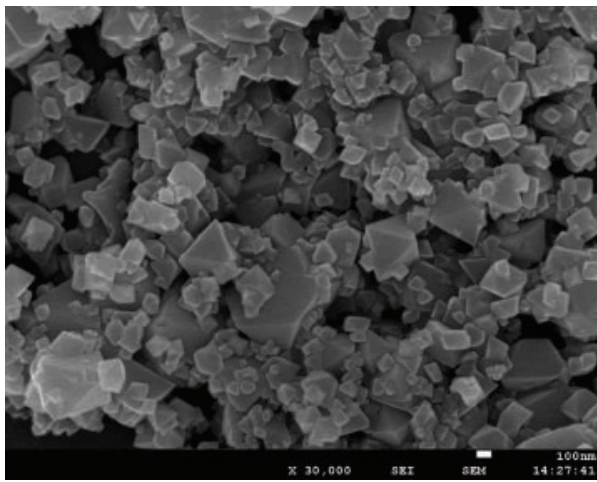

(a)

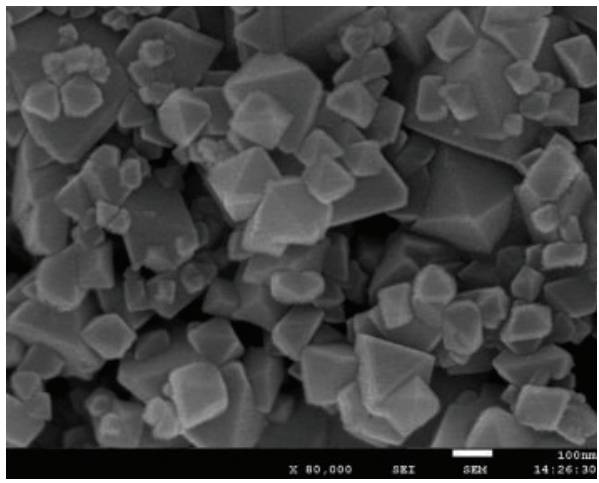

(c)

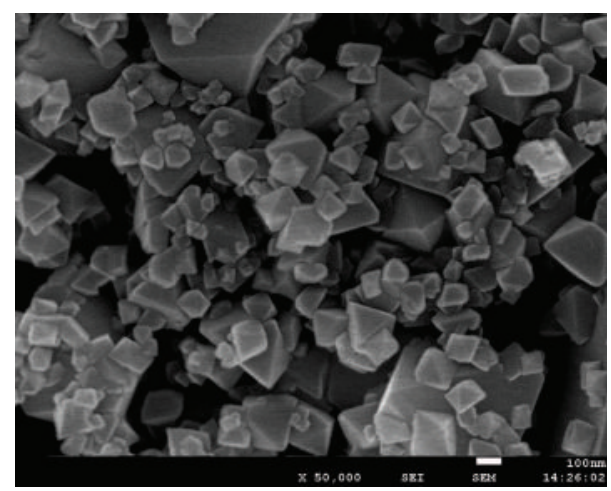

(b)

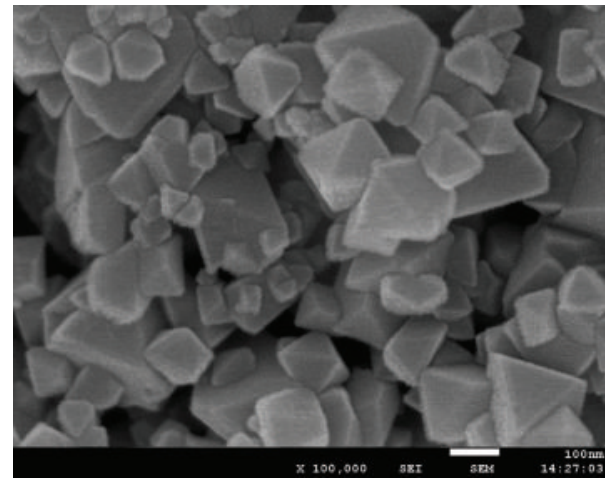

(d)

FIGURE 5: Representative SEM images under different magnification of the nanocrystals $\mathrm{MnCr}_{2} \mathrm{O}_{4}$ obtained by precursor calcined at $700^{\circ} \mathrm{C}$ for $3 \mathrm{~h}$.

in situ was completed in an instant to form a thin layer of salt crust on the surface of the newly formed nanoparticles. After the rapid cooling, the salt-coated particles were trapped in the salt matrix, which prevented the reagglomeration of the particles. Therefore, the introduction of $\mathrm{LiCl}$ in the process of traditional solution combustion reaction could effectively prevent nanocrystallites from forming the inseparable threedimensional network during the calcination. Instead, welldispersed nanoparticles were formed.

3.6. EDS Analysis. EDS was used to further confirm the composition of the obtained samples. The EDS analysis of the obtained products indicates that $\mathrm{MnCr}_{2} \mathrm{O}_{4}$ nanocrystals are composed of manganese, chromium, and oxygen with an approximate molar ratio $\mathrm{Mn} / \mathrm{Cr} / \mathrm{O} \approx 1 / 2 / 4$, giving a stoichiometric formula of $\mathrm{MnCr}_{2} \mathrm{O}_{4}$ with no chemical segregation phenomenon (Figure 6).

\section{Conclusions}

Well-dispersed $\mathrm{MnCr}_{2} \mathrm{O}_{4}$ nanocrystals were successfully made by the salt-assisted combustion method at a relatively low temperature. The calcination temperature had an important effect on the crystal sizes and lattice distortion. TEM results indicated that the introduction of inert salt- $\mathrm{LiCl}$ into the solution combustion synthesis process broke up the network structure of agglomerated nanocrystallites and resulted

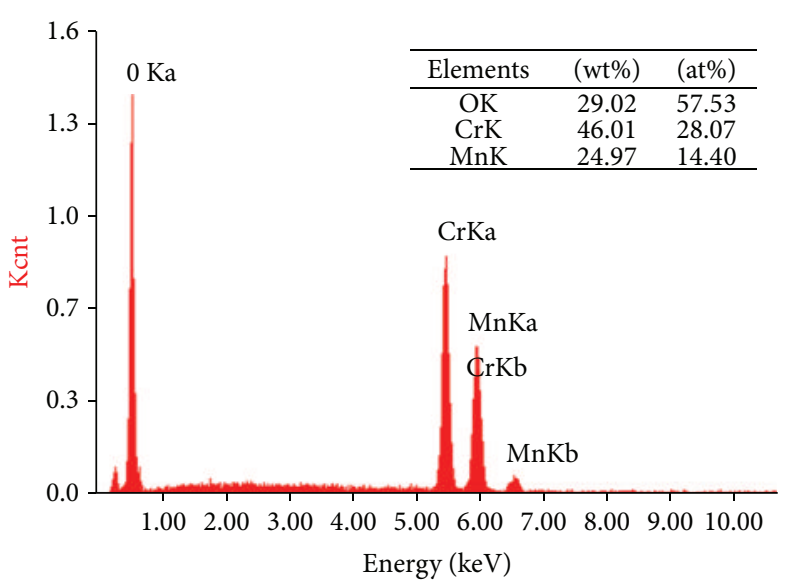

FIGURE 6: EDS analysis of $\mathrm{MnCr}_{2} \mathrm{O}_{4}$ nanocrystals obtained by precursor calcined at $700^{\circ} \mathrm{C}$ for $3 \mathrm{~h}$ via the salt-assisted method.

in the formation of well-dispersed nanocrystals. The developed procedure is simple and well controlled.

\section{Conflict of Interests}

The authors declare that there is no conflict of interests regarding the publication of this paper. 


\section{Acknowledgments}

The authors gratefully acknowledge the financial support of Key Programs for Science and Technology Development of Henan Province, China (no. 122102210239), the Fund for Young Teachers in Universities of Henan Province, China (2012GGJS-103), the Key Science and Technology Plan Projects of Zhengzhou City (no. 131PPTGG410-12), and the Natural Science Research Projects of Education Department of Henan Province, China (13B560115).

\section{References}

[1] K. Bhargav, S. Ram, N. Labhsetwar, and S. Majumder, "Correlation of carbon monoxide sensing and catalytic activity of pure and cation doped lanthanum iron oxide nano-crystals," Sensors and Actuators B: Chemical, vol. 206, pp. 389-398, 2015.

[2] X. Shang, L. Luo, K. Ren et al., "Synthesis and cytotoxicity of azo nano-materials as new biosensors for 1-Arginine determination," Materials Science and Engineering: C, vol. 51, pp. 279-286, 2015.

[3] R. Sadeghi, H. Karimi-Maleh, A. Bahari, and M. Taghavi, "A novel biosensor based on $\mathrm{ZnO}$ nanoparticle/1,3-dipropylimidazolium bromide ionic liquid-modified carbon paste electrode for square-wave voltammetric determination of epinephrine," Physics and Chemistry of Liquids, vol. 51, no. 6, pp. 704-714, 2013.

[4] Z. Karimi, L. Karimi, and H. Shokrollahi, "Nano-magnetic particles used in biomedicine: core and coating materials," Materials Science and Engineering C, vol. 33, no. 5, pp. 24652475, 2013.

[5] W. T. Li, T. Yuan, W. M. Zhang et al., "Influence of lithium precursors and calcination atmospheres on graphene sheetsmodified nano- $\mathrm{Li}_{4} \mathrm{Ti}_{5} \mathrm{O}_{12}$ anode material," Journal of Power Sources, vol. 285, pp. 51-62, 2015.

[6] R. P. Moyet, Y. Cardona, P. Vargas, J. Silva, and O. N. C. Uwakweh, "Coercivity and superparamagnetic evolution of high energy ball milled (HEBM) bulk $\mathrm{CoFe}_{2} \mathrm{O}_{4}$ material," Materials Characterization, vol. 61, no. 12, pp. 1317-1325, 2010.

[7] T. M. Sankaranarayanan, R. V. Shanthi, K. Thirunavukkarasu, A. Pandurangan, and S. Sivasanker, "Catalytic properties of spineltype mixed oxides in transesterification of vegetable oils," Journal of Molecular Catalysis A: Chemical, vol. 379, pp. 234-242, 2013.

[8] F. A. Jumeri, H. N. Lim, S. N. Ariffin et al., "Microwave synthesis of magnetically separable $\mathrm{ZnFe}_{2} \mathrm{O}_{4}$-reduced graphene oxide for wastewater treatment," Ceramics International, vol. 40, no. 5, pp. 7057-7065, 2014.

[9] D. Chanda, J. Hnát, M. Paidar, and K. Bouzek, "Evolution of physicochemical and electrocatalytic properties of $\mathrm{NiCo}_{2} \mathrm{O}_{4}$ $\left(\mathrm{AB}_{2} \mathrm{O}_{4}\right)$ spinel oxide with the effect of Fe substitution at the A site leading to efficient anodic $\mathrm{O}_{2}$ evolution in an alkaline environment," International Journal of Hydrogen Energy, vol. 39, no. 11, pp. 5713-5722, 2014.

[10] K. J. A. Aswad, N. R. H. Aziz, and H. A. Koyi, "Cr-spinel compositions in serpentinites and their implications for the petrotectonic history of the Zagros Suture Zone, Kurdistan Region, Iraq," Geological Magazine, vol. 148, no. 5-6, pp. 802-818, 2011.

[11] Y. H. Zhou, Z. R. Yang, L. Li et al., "Magnetic field and external pressure effects on the spiral order of polycrystalline $\mathrm{MnCr}_{2} \mathrm{O}_{4}$," Journal of Magnetism and Magnetic Materials, vol. 324, no. 22, pp. 3799-3801, 2012.
[12] S. A. Hosseini, M. C. Alvarez-Galvan, J. L. G. Fierro, A. Niaei, and D. Salari, "MCr2O4 $(\mathrm{M}=\mathrm{Co}, \mathrm{Cu}$, and $\mathrm{Zn})$ nanospinels for 2propanol combustion: correlation of structural properties with catalytic performance and stability," Ceramics International, vol. 39, no. 8, pp. 9253-9261, 2013.

[13] K. Premalatha, P. S. Raghavan, and B. Viswanathan, "Liquid phase oxidation of benzyl alcohol with molecular oxygen catalyzed by metal chromites," Applied Catalysis A: General, vol. 419-420, pp. 203-209, 2012.

[14] H. Li and W. Chen, "Stability of $\mathrm{MnCr}_{2} \mathrm{O}_{4}$ spinel and $\mathrm{Cr}_{2} \mathrm{O}_{3}$ in high temperature carbonaceous environments with varied oxygen partial pressures," Corrosion Science, vol. 52, no. 7, pp. 2481-2488, 2010.

[15] Q. Diao, C. Yin, Y. Guan et al., "The effects of sintering temperature of $\mathrm{MnCr}_{2} \mathrm{O}_{4}$ nanocomposite on the $\mathrm{NO}_{2}$ sensing property for YSZ-based potentiometric sensor," Sensors and Actuators B: Chemical, vol. 177, pp. 397-403, 2013.

[16] H. Li, Y. J. Zheng, L. W. Benum, M. Oballa, and W. Chen, "Carburization behaviour of $\mathrm{Mn}-\mathrm{Cr}-\mathrm{O}$ spinel in high temperature hydrocarbon cracking environment," Corrosion Science, vol. 51, no. 10, pp. 2336-2341, 2009.

[17] H. Li and W. X. Chen, "Stability of $\mathrm{MnCr}_{2} \mathrm{O}_{4}$ spinel and $\mathrm{Cr}_{2} \mathrm{O}_{3}$ in high temperature carbonaceous environments with varied oxygen partial pressures," Corrosion Science, vol. 52, no. 7, pp. 2481-2488, 2010.

[18] Y. P. Wang, J. W. Zhu, L. L. Zhang, X. Yang, L. Lu, and X. Wang, "Preparation and characterization of perovskite $\mathrm{LaFeO}_{3}$ nanocrystals," Materials Letters, vol. 60, no. 13-14, pp. 1767-1770, 2006.

[19] Y. P. Tong, S. B. Zhao, W. F. Feng, and L. Ma, "A study of Eudoped $\mathrm{La}_{2} \mathrm{Zr}_{2} \mathrm{O}_{7}$ nanocrystals prepared by salt-assistant combustion synthesis," Journal of Alloys and Compounds, vol. 550, pp. 268-272, 2013.

[20] Y. P. Tong, S. B. Zhao, L. Ma, W. X. Zhao, W. H. Song, and H. Yang, "Facile synthesis and crystal growth dynamics study of $\mathrm{MgAl}_{2} \mathrm{O}_{4}$ nanocrystals," Materials Research Bulletin, vol. 48, no. 11, pp. 4834-4838, 2013.

[21] F. L. Song, L. R. Huang, D. H. Chen, and W. Tang, "Preparation and characterization of nanosized $\mathrm{Zn}$-Co spinel oxide by solid state reaction method," Materials Letters, vol. 62, no. 3, pp. 543$547,2008$. 

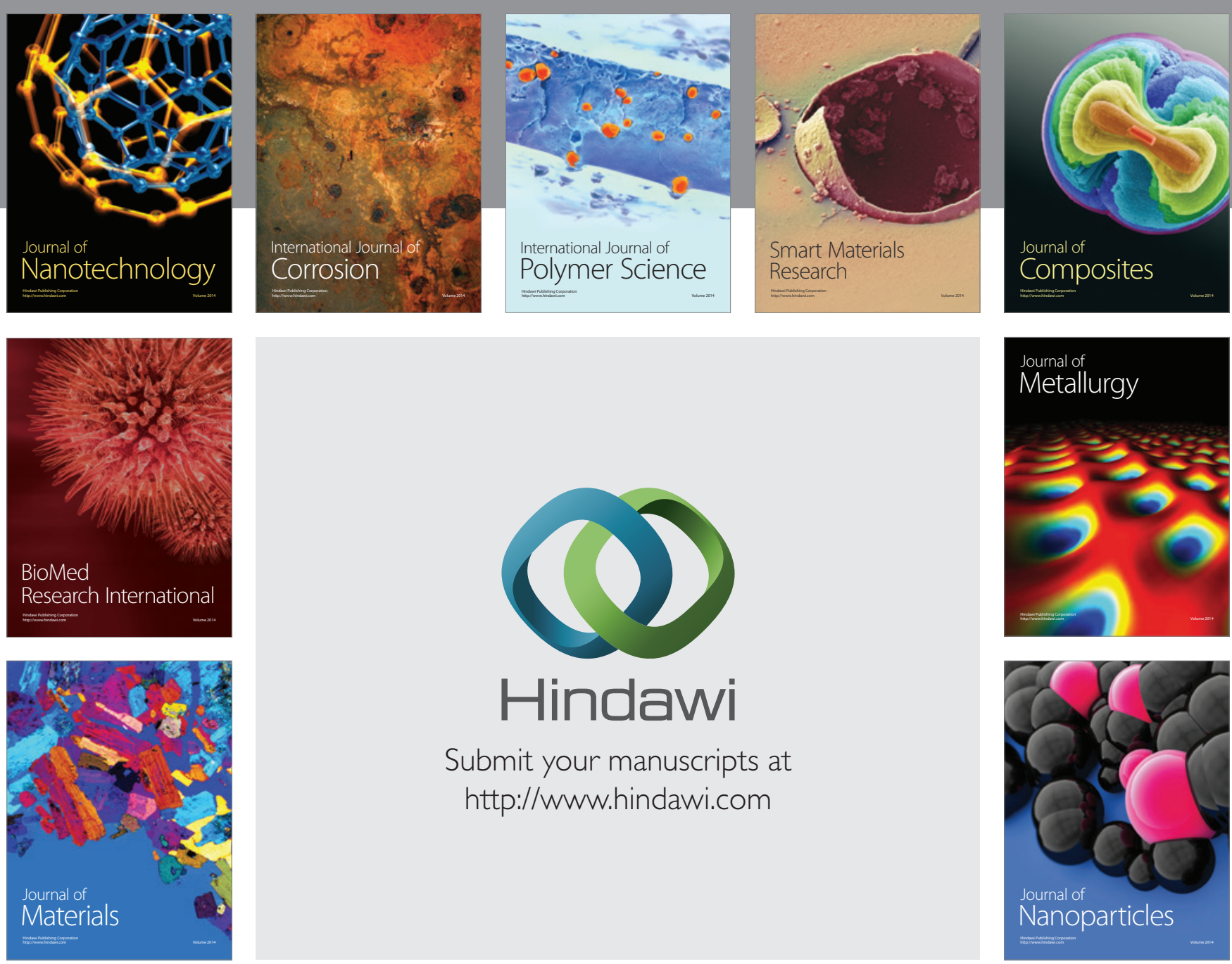

Submit your manuscripts at http://www.hindawi.com
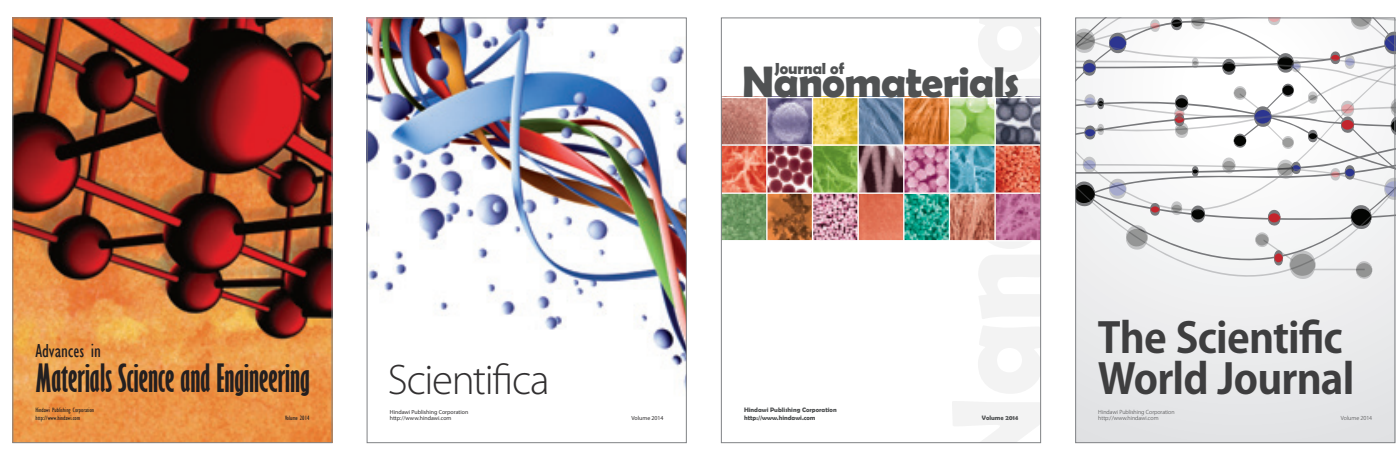

\section{The Scientific World Journal}
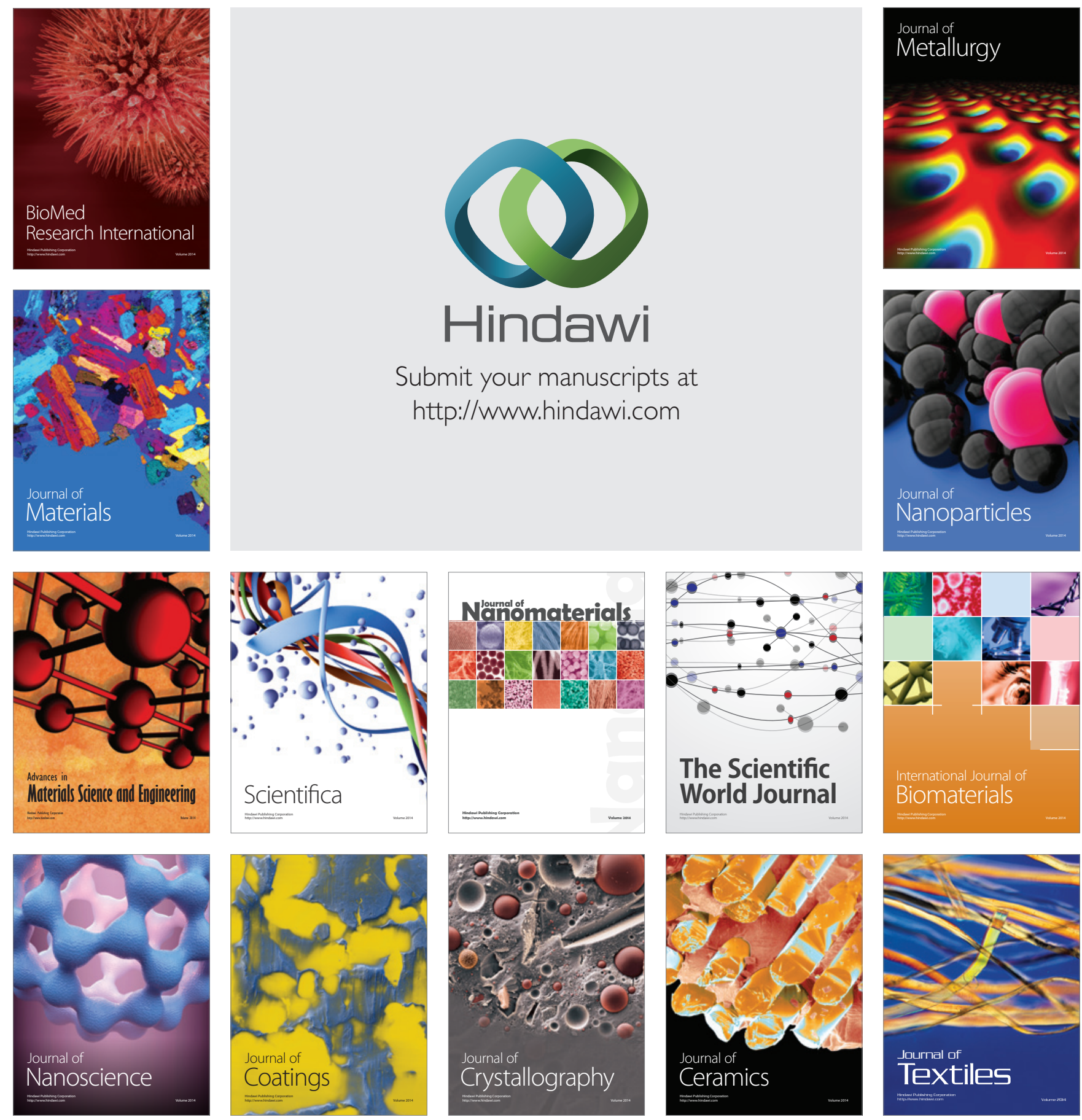